\section{Aims and Scope:}

The Journal of the International Neuropsychological Society welcomes original, creative, high quality research papers covering all areas of neuropsychology. The focus of articles may be primarily experimental, more applied or clinical. Contributions will broadly reflect the interest of all areas of neuropsychology, including but not limited to: development of cognitive processes, brain-behavior relationships, adult and pediatric neuropsychology, neurobehavioral syndromes, such as aphasia or apraxia, and the interfaces of neuropsychology with related areas such as behavioral neurology, neuropsychiatry, and cognitive neuroscience. Papers that utilize behavioral, neuroimaging, and electrophysiological measures are appropriate. Book reviews will also be published.

To assure maximum flexibility and to promote diverse mechanisms of scholarly communication, the following formats are available in addition to Regular Research Articles: Brief Communications are shorter research articles; Rapid Communications are intended for "fast breaking" new work, that does not yet justify a full length article, and which are put on a fast review track; Neurobehavioral Grand Rounds are unique case studies, which are published in tandem with an introduction by an expert in the field to put the case into a more global perspective; Critical Reviews are thoughtful considerations of topics of importance to neuropsychology, including associated areas, such as functional brain imaging, neuroepidemiology, and ethical issues; Dialogues provide a forum for publishing two distinct positions on controversial issues in a point-counterpoint form; Symposia consist of several research articles that are thematically linked; Letters to the Editor respond to recent articles in the Journal of the International Neuropsychological Society; and Book Reviews.

Critical Reviews, Dialogues, and Symposia may be invited by the appropriate Department Editor or proposed by individual authors. Such proposals should be discussed with the Editor-in-Chief or the Department Editor before submission. Book Reviews are invited by the Book Review Editor.

\section{Originality and Copyright}

To be considered for publication in the Journal of the International Neuropsychological Society, a manuscript cannot have been published previously, nor can it be under review for publication elsewhere. Papers with multiple authors are reviewed with the assumption that all authors have approved the submitted manuscript and concur with its submission to the Journal of the International Neuropsychological Society. A Copyright Transfer Agreement, with certain specified rights reserved by the author, must be signed and returned to the Editor by the corresponding author of accepted manuscripts, prior to publication. This is necessary for the wide distribution of research findings, and the protection of both author and the society under copyright law.

If you plan to include material that has been published elsewhere and is under copyright of a third party, you will need to obtain permission to re-use this material in your article. A form is provided for this purpose. Alternatively, many publishers use an online system for such requests. It is the responsibility of the authors to obtain permissions to re-use material from elsewhere.

\section{Disclosure Form}

The Author Disclosure Form must be signed by the corresponding author for all the manuscript's authors at the time the manuscript is submitted. This form includes an attestation that the manuscript is original and not under review in another journal, research was conducted in compliance with institutional guidelines, and any potential conflicts of interest have been reported. Such disclosure will not preclude publication, but it is critical because of the potential of negative or positive bias. Potential conflicts of interest include funding sources for the reported study (e.g., a test validation study financially supported by a test publisher, a study supported by an insurance company), personal or family financial interest in a test or product or with a company that publishes a test that is being investigated in the manuscript or competes with a test that is being investigated in the manuscript. Other conflicts include employment, consultancies, stock ownership or medicolegal work. For the latter, information about whether the author's medicolegal work is largely for one side should be reported. This list of potential conflicts is not all inclusive, and it is the responsibility of each author to ensure that all of their "potential conflicts" are reported in the Acknowledgment section of the paper. Authors should err on the side of full disclosure, and if authors are uncertain about what constitutes a relevant conflict, they should contact the editorial office (jins@unm.edu).

In addition to signing this attestation, compliance with institutional research standards for animal or human research (including a statement that the research was completed in accordance with the Helsinki Declaration http://www.wma.net/e/policy/17-c_e.html) should be included in the methods section of the manuscript, and funding sources and other potential conflicts of interest should be included in the acknowledgments.

Only the corresponding author's signature is required. This disclosure form pertains to all authors, and the corresponding author's signature documents that the corresponding author has obtained all pertinent information from all authors. It is the corresponding author's ethical responsibility to explicitly check with each of his/her co-authors to ensure that any real or apparent conflict of interest is appropriately disclosed. The intent of this disclosure is not to prevent an author with a significant financial or other relationship from publishing their work in JINS, but rather to provide readers with information on which they can make their own judgments.

\section{Manuscript Submission and Review}

The Journal of the International Neuropsychological Society uses online submission and peer review. Paper submissions are not accepted. Authors who are not able to submit their manuscripts online are asked to contact the editorial office at: jins@unm.edu. The website address for submissions is: http://mc. manuscriptcentral.com/cup/jins, and complete instructions are provided on the website. Prior to online submission, please consult http://www.ncbi.nlm. nih.gov/entrez/query.fcgi?db=mesh for 6 keywords or mesh terms that are different from words in the title. Accurate mesh terms will increase the probability that your manuscript will be identified in online searches. Please follow the instructions carefully to avoid delays. The menu will prompt the author to provide all necessary information, including the manuscript category, the corresponding author including phone number, fax number and e-mail address, and suggested reviewers.

The website will automatically acknowledge receipt of the manuscript and provide a manuscript reference number. The Editor-in-Chief will assign the manuscript for review to an Associate or Department Editor and at least two other reviewers. Every effort will be made to provide the author with a review within 6 to 10 weeks of manuscript assignment. Rapid Communications will be reviewed within 6 weeks. If the Editor requests that revisions be made to a manuscript before publication, a maximum of 3 months will be allowed for preparation of the revision, except in unusual circumstances.
Required Disclosure, Copyright Transfer, and Permissions Forms

Upon submission of your manuscript, you will be sent an e-mail requesting a signed Author Disclosure form. The Author Disclosure form will be included in the e-mail. Also included in this e-mail will be instructions on how to fax or e-mail the form to the JINS office.

Upon acceptance of your manuscript, you will be sent an e-mail requesting a signed Transfer of Copyright form and instructions on how to fax or e-mail the form will be included in the e-mail. You will also be requested to provide original copies of permissions to re-use material that has been published elsewhere. You may use the form, or the wording contained in it, to seek permission from other publishers, or use the publisher's online request system if this is preferred.

\section{Rights and Permissions}

For information regarding rights and permissions concerning JINS, contact Marc Anderson (manderson@ cambridge.org), or Adam Hirschberg (ahirschberg@ cambridge.org).

\section{Manuscript Length}

In order to increase the number of manuscripts that can be published in the JINS, please adhere to the following length requirements. Please provide a word count on the title page for abstract and for manuscript (not including abstract, tables, figures, or references). Manuscripts will be returned if they exceed length requirements.

Regular Research Articles: Maximum of 5,000 words (not including tables, figures, or references) and a 200 word abstract.

Brief Communications: Maximum of 2,500 words (not including abstract, tables, figures, or references) and a 150 word abstract, with a maximum of two tables or two figures, or one table and one figure, and 20 references.

Rapid Communications: Maximum of 1,000 words (not including abstract, tables, figures, or references) and a 150 word abstract, with a maximum of two tables or two figures, or one table and one figure, and 10 references.

Critical Reviews: Maximum of 7,000 words (not including abstract, tables, figures, or references) and a 200 word abstract. Critical Reviews must be preapproved by the Department Editor. Please e-mail your abstract to jins@unm.edu in order to receive prior approval.

Short Reviews: Maximum of 2,500 words, a 100word abstract, and 35 references. Short Reviews are conceptually-oriented snapshots of the current state of a research area rather than comprehensive reviews. We welcome descriptions of new or recent concepts and their applicability to neuropsychology, and proposals of novel ideas or approaches, particularly if they lead to testable hypotheses. Prose should be readily accessible to both students and seasoned scientists and clinicians. Short Reviews are written by recognized experts in their field. Generally, they are submitted by invitation only, but occasionally an invitation may be issued on the basis of an unsolicited proposal.

Dialogues: Maximum of 2,000 words for each segment (not including abstract, tables, figures, or references) and a 100 word abstract, with a maximum of two tables or two figures, or one table and one figure and 20 references. Dialogues must be preapproved by the Department Editor. Please e-mail your abstract to jins@unm.edu in order to receive prior approval. 
Symposia: Maximum of 5,000 words (not including abstract, tables, figures, or references) and a 200 word abstract. Symposia must be pre-approved by the Department Editor. Please e-mail your abstract to jins@unm.edu in order to receive prior approval.

Neurobehavioral Grand Rounds: Maximum of 5,000 words with an informative literature review (not including abstract, tables, figures, or references) and a 200 word abstract.

Letters to the Editor: Maximum of 500 words (not including table, figure, or references) with up to five references, one table, or one figure.

Book Reviews: Approximately 1,000 words.

\section{Manuscript Preparation and Style}

The entire manuscript should be typed double-spaced throughout using any word processing program. Unless otherwise specified, the guideline for preparation of manuscripts is the Publication Manual of the American Psychological Association (6th edition). This may be ordered from: APA Order Dept., 750 1st St. NE, Washington, DC 20002-4242, USA.

Pages should be numbered sequentially beginning with the Title Page. The Title Page should contain the full title of the manuscript, the full names and affiliations of all authors, a contact address with telephone and fax numbers and e-mail address, and the word count for abstract and for manuscript (excluding title page, abstract, references, tables, and figures). At the top right provide a short title of up to 45 characters preceded by the lead author's last name. Example: Smith-Memory in Parkinson's Disease. This running headline should be repeated at the top right of every following page.

The Abstract and Mesh terms (Keywords) on page 2 should include a brief statement of the problem, the method, the key findings, and the conclusions. Six mesh or key words should be provided (see http:// www.ncbi.nlm.nih.gov/entrez/query.fcgi? $\mathrm{db}=$ mesh for list), and they should not duplicate words in the title.

The full text of the manuscript should begin on page 3. For scientific articles, including Regular Research Articles, Brief Communications, Rapid Communications, and Symposia, the format should include an Abstract, Introduction, Method, Results, and Discussion. This should be followed by References, Appendixes, Acknowledgments, Tables, Figures, and Figure Legends.

The use of abbreviations, except those that are widely used, is strongly discouraged. They should be used only if they contribute to better comprehension of the manuscript. Acronyms should be spelled out at firs mention. Metric system (SI) units should be used.

\section{Special Note Regarding Figures}

Please upload your figure(s) in either a .doc or pdf. format. When uploading figures (color or black and white), they need only be a high enough resolution for the reviewers and editors to identify the information you are trying to convey. However, if your manuscript is accepted for publication, your figures must meet the following criteria:

High quality digital images (600 dpi or higher) should be provided in PDF, EPS, or TIFF formats. If a digital image is not available, please scan in the image. Figures should be numbered consecutively as they appear in the text. Any indication of features of special interest should also be included. Figures should be twice their intended final size and authors should do their best to construct figures with notation and data points of sufficient size to permit legible photo reduction to one column of a two-column format.

Color figures can be accepted. All color graphics must be formatted in CMYK and not in RGB, because 4-color separations cannot be done in RGB. However, the extra cost of printing these figures must be paid by the author: $\$ 500$ for the first color page, $\$ 250$ for each color page thereafter.

Tables and figures should be numbered in Arabic numerals. The approximate position of each table and figure should be provided in the manuscript: [INSERT TABLE 1 HERE]. Tables and figures should be on separate pages. Tables should have short titles and all figure legends should be on separate pages.

If you plan to use figures or tables that have been redrawn or modified from other publications, and you are not the copyright holder, please obtain permission for this re-use. Authors should err on the side of caution and seek advice from the editorial office if they are uncertain whether to seek permission.

\section{Financial Support}

Please provide details of the sources of financial support for all authors, including grant numbers. For example, "This work was supported by the National Institutes of Health (grant number XXXXXXX)". Multiple grant numbers should be separated by a comma and space, and where research was funded by more than one agency the different agencies should be separated by a semi-colon, with "and" before the final funder. Grants held by different authors should be identified as belonging to individual authors by the authors' initials. For example, "This work was supported by the Wellcome Trust (A.B., grant numbers XXXX, YYYY), (C.D., grant number ZZZZ); the Natural Environment Research Council (E.F., grant number FFFF); and the National Institutes of Health (A.B., grant number GGGG), (E.F., grant number HНHН)." Where no specific funding has been provided for research, please provide the following statement "This research received no specific grant from any funding agency, commercial or not-for-profit sectors."

\section{References}

References should be in American Psychological Association, 6th Edition, style (see the examples presented below).

Text references should be cited as follows: ". . . Given the critical role of the prefrontal cortex (PFC) in working memory (Cohen et al., 1997; Goldman-Rakic, 1987; Perlstein et al., 2003a, 2003b) ..."with multiple references in alphabetical order. Another example is: "For example, Cohen et al. (1994,1997), Braver et al. (1997), and Jonides and Smith (1997) demonstrated . . .' References cited in the text with two authors should list both names. References cited in the text with three, four, or five authors, list all authors at first mention; with subsequent citations, include only the first author's last name followed by et al. References cited in the text with six or more authors should list the first author et al. throughout. In the reference section, list all authors up to seven. For eight or more, list the first six, then three ellipses, and end with the last author's name. Examples of the APA reference style are as follows:

Online/Electronic Journal Article with DOI:

Dikmen, S., Machamer, J. Fann, J. \& Temkin, N (2010). Rates of Symptom Reporting Following Traumatic Brain Injury. Journal of the International Neuropsychological Society, 16, 401-411. doi: 10.1017/S1355617710000196

Scientific Article:

Haaland, K.Y., Price, L., \& LaRue, A. (2003). What does the WMS-III tell us about memory changes with normal aging? Journal of the International Neuropsychological Society, 9, 89-96.

Book:

Lezak, M.D., Howieson, D.B., \& Loring, D.W. (2004). Neuropsychological Assessment. New York: Oxford University Press.

\section{Book Chapter:}

Knopman, D. \& Selnes, O. (2003). Neuropsychology of Dementia. In K.M. Heilman \& E.E. Valenstein (Ed.), Clinical Neuropsychology. New York: Oxford University Press.

\section{Report at a Scientific Meeting:}

Rothi, L.J.G. (2003, February). Use-dependent learning and neural plasticity: A revision of the pessimism surrounding neurorehabilitation. International Neuropsychological Society, Honolulu, Hawaii.

Manual, Diagnostic Scheme, etc.:

American Psychiatric Association (1994). Diagnostic and Statistical Manual of Mental Disorders (4th ed.). Washington, DC: American Psychiatric Association Press.

Proofs

The publisher reserves the right to copyedit manuscripts. The corresponding author will receive PDFs for final proofreading. These should be checked and corrections returned within 2 days of receipt. The publisher reserves the right to charge authors for excessive corrections.

\section{Offprints and PDF Files}

The corresponding author will receive a free pdf. This pdf can also be mounted on the authors' web pages. Offprints must be ordered when page proofs are returned. The offprint order form with the price list will be sent with your PDF. 
1. Publication Title @ (All Periodicals Publications Except Requester Publications) JINS Journal of the International Neuropsychological 4. Issue Frequency $\frac{\text { Bimonthly Jan, Mar, May, Jul, Sep, Nov }}{7 . \text { Complete Mailing Address of Known Office of Publication (Not printer) (Street, city, county, state, }}$

Cambridge University Press

32 Avenue of the Americas, New York, NY 10013-2473

8. Complete Mailing Address of Headquarters or General Business Office of Publisher (Not printer) 3. Filing Date Annual Subscription Price \begin{tabular}{l|c}
6 & $\$ 705.00$ \\
\hline and ZIP+4(8) & Contact Person
\end{tabular}

Cambridge University Press

9. Full Names and Complete Mailing Addresses of Publisher, Editor, and Managing Editor (Do not leave blank)

Cambridge university press

32 Avenue of the Americas, New York, NY 10013-2473

Editor (Name and complete mailing address)

Editor-in-Chief, Kathleen Y. Haaland, Ph.D. , NM VA Healthcare System, University of New Mexico, Albuquerque, $\mathrm{NM}, \mathrm{USA}$

Managing Editor (Name and complete mailing address)

Simon Ross, Cambridge University Press, Edinburgh Building, Cambridge CB2 2RU, England

\begin{tabular}{|c|c|}
\hline \multicolumn{2}{|c|}{ 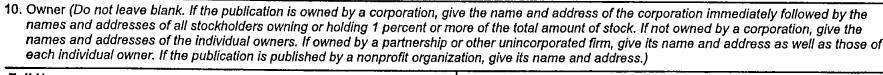 } \\
\hline Full Name & Complete Malling Address \\
\hline \multirow[t]{2}{*}{ International Neuropsychological Society } & 700 Ackerman Rd, Suite 625 \\
\hline & Columbus, OH $43202-1559$ \\
\hline & \\
\hline & \\
\hline \multicolumn{2}{|c|}{$\begin{array}{l}\text { 11. Known Bondholders, Mortgagees, and Other Security Holders Owning or } \\
\text { Holding } 1 \text { Percent or More of Total Amount of Bonds, Mortgages, or } \\
\text { Other Securitites. If none, check box }\end{array}$} \\
\hline \multirow[t]{5}{*}{ Full Name } & Complete Mailing Address \\
\hline & \\
\hline & \\
\hline & \\
\hline & \\
\hline \multicolumn{2}{|c|}{$\begin{array}{l}\text { 12. Tax Slatus (For completion by nonprofft organizations authorized to mail a t nonprofit rates) (Check one) } \\
\text { The purpose, function, and nonprofit status of this organization and the exempt status for federal income tax purposes: }\end{array}$} \\
\hline \multicolumn{2}{|c|}{ 口 Has Not Changed During Preceding 12 Months } \\
\hline \multicolumn{2}{|c|}{ Has Changed During Preceding 12 Months (Publisher must submit explanatton of change with this statement) } \\
\hline
\end{tabular}

\begin{tabular}{|c|c|c|c|c|}
\hline \multirow{2}{*}{\multicolumn{3}{|c|}{$\begin{array}{l}\text { 13. Publication Title } \\
\text { JINS Journal of the International Neuropsychological Society } \\
\text { 15. Extent and Nature of Circulation }\end{array}$}} & \multicolumn{2}{|c|}{$\begin{array}{l}\text { 14. Issue Date for Circulation Data Below } \\
09 / 10\end{array}$} \\
\hline & & & \multirow[t]{2}{*}{$\begin{array}{l}\text { Average No. Copies Each Issue } \\
\text { During Preceding } 12 \text { Months }\end{array}$} & $\begin{array}{l}\text { No. Copies of Single Issue } \\
\text { Published Nearest to } \\
\text { Flling Date }\end{array}$ \\
\hline \multicolumn{3}{|c|}{ a. Total Number of Copies (Net press run) } & & 105 \\
\hline \multirow{4}{*}{$\begin{array}{l}\text { b. Paid } \\
\text { Circulation } \\
\text { (By Mall } \\
\text { and } \\
\text { Outside } \\
\text { the Mall) }\end{array}$} & (1) & $\begin{array}{l}\text { Mailed Outside-County Paid Subscriplions Stated on } \\
\text { PS Form 3541(lnclude paid distribution above noml- } \\
\text { nal artet, advertiser's proof copies, and exchange } \\
\text { copies) }\end{array}$ & 1,222 & 466 \\
\hline & (2) & 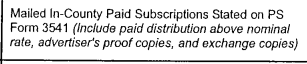 & 0 & \\
\hline & (3) & 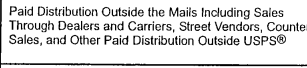 & 443 & 222 \\
\hline & (4) & $\begin{array}{l}\text { Paid Distribution by Other Classes of Mail Through } \\
\text { the USPS (e.g. First-Class MailQ) }\end{array}$ & 0 & \\
\hline \multicolumn{3}{|c|}{ c. Total Paid Distribution (Sum of 15b (1), (2), (3), and (4)) } & 1,665 & 688 \\
\hline \multirow{4}{*}{$\begin{array}{l}\text { d. Free or } \\
\text { Nominal } \\
\text { Rate } \\
\text { Distribution } \\
\text { (By Mail } \\
\text { and } \\
\text { Outside } \\
\text { the Mail) }\end{array}$} & (1) & $\begin{array}{l}\text { Free or Nominal Rate Outside-County } \\
\text { Copies included on PS Form } 3541\end{array}$ & 33 & 77 \\
\hline & (2) & $\begin{array}{l}\text { Free or Nominal Rate In-County Copies Included } \\
\text { on PS Form } 3541\end{array}$ & 0 & \\
\hline & (3) & $\begin{array}{l}\text { Free or Nominal Rate Copies Mailed at Other } \\
\text { Classes Through the USPS (e.g. First-Class Mail) }\end{array}$ & 0 & \\
\hline & (4) & $\begin{array}{l}\text { Free or Nominal Rate Distribution Outside the Mail } \\
\text { (Carriers or other means) }\end{array}$ & 35 & -38 \\
\hline \multicolumn{3}{|c|}{ e. Total Free or Nominal Rate Distribution (Sum of 15d (1), (2), (3) and (4)) } & 68 & 115 \\
\hline \multicolumn{3}{|c|}{ f. Total Distribution (Sum of 15c and 15e) } & 1,733 & 803 \\
\hline \multicolumn{3}{|c|}{ g. Copies not Distributed (See Instructions to Publishers \#4 (page \#3)) } & 239 & 302 \\
\hline \multicolumn{3}{|c|}{ h. Total (Sum of $15 f$ and $g$ ) } & .972 & 1,105 \\
\hline \multicolumn{3}{|c|}{$\begin{array}{l}\text { i. } \begin{array}{l}\text { Percent Paid } \\
\text { (15c divided by } 15 f \text { times } 100)\end{array} \\
\end{array}$} & $96 \%$ & \\
\hline \multicolumn{4}{|c|}{$\begin{array}{l}\text { If the publication is a general publication, publication of this statement is required. Will be printed } \\
\text { in the }\end{array}$} & \\
\hline \multicolumn{4}{|c|}{ Hume Barksolue } & $10 / 15 / 2010$ \\
\hline \multicolumn{5}{|c|}{ 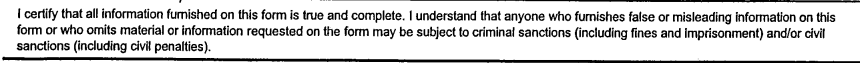 } \\
\hline
\end{tabular}




\section{CAMBRIDGE}

\section{Outstanding New Scholarship from Cambridge!}

Latent Inhibition

Cognition, Neuroscience and Applications to Schizophrenia

R. E. LuBOW and INA WEINER

\$125.00: Hb: 978-0-521-51733-1: 576 pp.

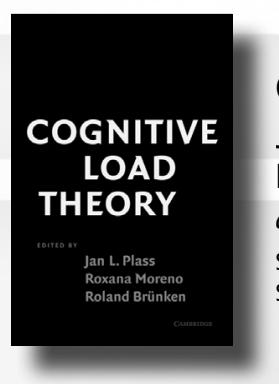

Language, Usage and Cognition

JoAN BYbeE

\$99.00: Hb: 978-0-521-85140-4: $262 \mathrm{pp}$. \$39.99: Pb: 978-0-521-61683-6

Cognitive Load Theory

JAN L. PLASS,

Roxana Moreno, and ROLAND BRÜNKEN

\$90.00: Hb: 978-0-521-86023-9: $288 \mathrm{pp}$.

\$29.99: Pb: 978-0-521-67758-5
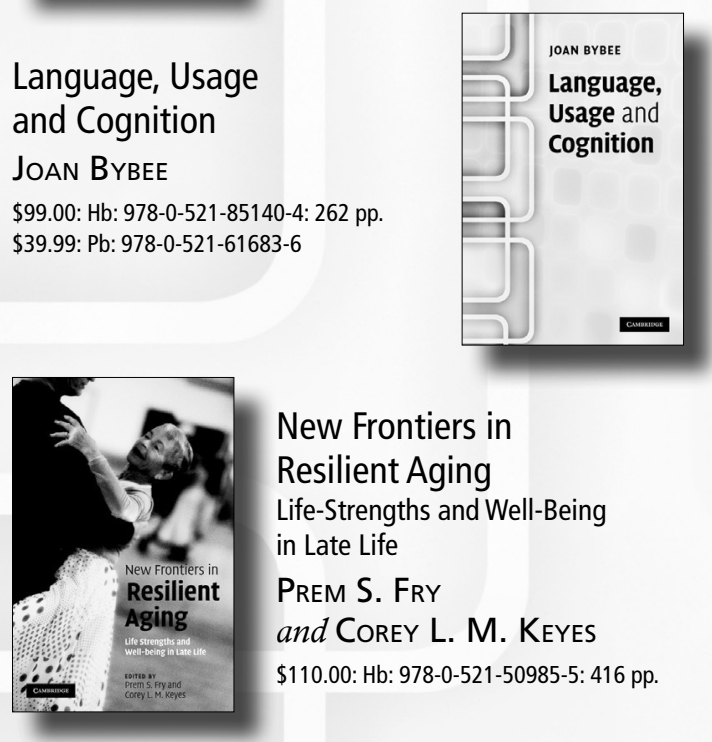

New Frontiers in

Resilient Aging

Life-Strengths and Well-Being

in Late Life

Prem S. Fry

and CoReY L. M. Keyes

\$110.00: Hb: 978-0-521-50985-5: 416 pp.

Memory,

War and Trauma

Nigel C. Hunt

\$99.00: Hb: 978-0-521-88784-7: $248 \mathrm{pp}$ \$34.99: Pb: 978-0-521-71625-3

Prices subject to change.

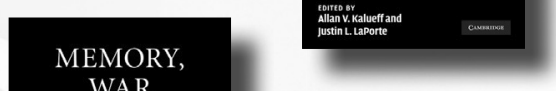

Now in Paperback!

Developmental Contexts

in Middle Childhood

Bridges to Adolescence and Adulthood

Aletha C. Huston

and MARIKA N. RIPKE

Cambridge Studies in

Social and Emotional Development

\$32.99: Pb: 978-0-521-17554-8: 478 pp.

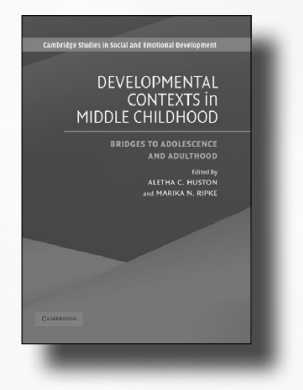

Third Edition!

Nerve Cells and

Animal Behaviour

Peter J. Simmons

and DAVID YounG

\$110.00: Hb: 978-0-521-89977-2: 292 pp. \$45.00: Pb: 978-0-521-72848-5

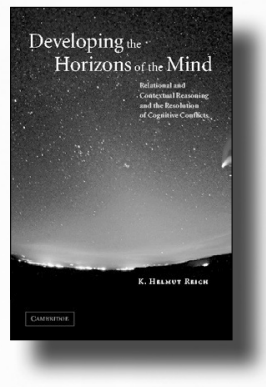

Disturbances of the Mind

Douwe Draaisma

Translated by

BARBARA FASTING

\$25.99: Hb: 978-0-521-50966-4: 366 pp.

Experimental Models

in Serotonin

Transporter Research

Allan V. Kaluefr

and JUSTIN L. LAPORTE

\$110.00: Hb: 978-0-521-51487-3: $380 \mathrm{pp}$

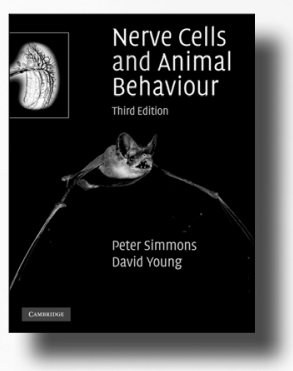




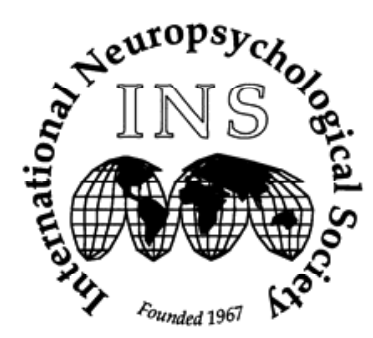

\title{
Call for Abstracts
}

\author{
International Neuropsychological Society \\ Mid-Year Meeting \\ July 6-9, 2011 \\ Sky City \\ Auckland, New Zealand
}

Program Chairs: Skye McDonald, Lynette Tippett

Director of Continuing Education: Jennifer Manly

\section{Online Submission Available: October 1, 2010 Abstract Submission Deadline: January 31, 2011}

\section{http://insmidyear.abstractcentral.com}

\section{Message from Skye McDonald \& Lynette Tippett Program Co-Chairs}

We welcome you to a very special midyear meeting of the INS to be held in Auckland, New Zealand. This meeting is the 4th Pacific Rim Meeting, held in conjunction with the INS and the Australian Society for the Study of Brain Impairment (ASSBI). It is the first time we have held a meeting in the beautiful country of New Zealand, a country renowned for its wild and dramatic landscape and rich Maori culture.

The meeting promises to be a stimulating and rewarding experience, mixing workshops, keynote speakers and free papers on any topic relevant to brain impairment, its assessment and remediation, ranging from theoretical to applied issues. The theme of this meeting is "The Social Brain."

This has been chosen to reflect growing interest in the neuropsychology of social processes as well as the need to consider assessment and remediation in context. We especially encourage submissions that report cutting edge research in all facets of neuropsychology from basic research through to rehabilitation and outcomes that address social functioning.

Alongside this theme we welcome submissions more broadly from all fields of neuropsychology, neuroscience and rehabilitation. We have a fantastic line up of key-note speakers and workshops in our Continuing Education program. 
1099 Coordinated and Circumlocutory Semantic Naming Errors Are Related to Anterolateral Temporal Lobes in Mild AD, Amnestic Mild Cognitive Impairment, and Normal Aging

1108 Role of Alexithymia in Suicide Ideation after Traumatic Brain Injury

1115 Everyday Memory: Self-Perception and Structural Brain Correlates in a Healthy Elderly Population

1127 Facial Emotion Recognition Impairments in Individuals with HIV

1138 Effects of Education, Literacy, and Dementia on the Clock Drawing Test Performance

\section{BRIEF COMMUNICATION}

1147 Retrieval Practice: A Simple Strategy for Improving Memory after Traumatic Brain Injury

\section{LETTERS TO THE EDITOR}

1151 My Head Hurts Just Thinking About it

1153 Neurobiological Aspects of Complex Regional Pain Syndrome (CRPS): Reply to Victor, Boone, and Kulick (2010)

\section{BOOK REVIEWS}

1155 Review of "Child Neuropsychology: Concepts, Theory, and Practice," Jonathan Reed and Jody Warner-Rogers (Eds.).

1156 Review of "Neuropsychological Assessment of Neuropsychiatric and Neuromedical Disorders (3rd Edition)," I. Grant and K.A. Adams (Eds.).

1157 Review of "Handbook of Rehabilitation Psychology (2nd Edition)," Robert G. Frank, Mitchell Rosenthal, and Bruce Caplan (Eds.).

1159 Recent and Relevant

\section{INDEX/CONTENTS/REVIEWERS}

1163 Index to Authors/Keywords/Titles

1178 Volume 16, 2010 Contents

1187 Acknowledgments to JINS External Reviewers
M.L.F. Balthazar, C.L. Yasuda, F.R.S. Pereira, F.P.G. Bergo, F. Cendes, and B.P. Damasceno

R.LL. Wood, C. Williams, and R. Lewis

A. Bjфrnebekk, L.T. Westlye, K.B. Walhovd, and A.M. Fjell

U.S. Clark, R.A. Cohen, M.L. Westbrook, K.N. Devlin, and K.T. Tashima

H. Kim and J. Chey

J.F. Sumowski, H.G. Wood, N. Chiaravalloti, G.R. Wylie, J. Lengenfelder, and J. DeLuca

T.L. Victor, K.B. Boone, and A.D. Kulick

D.J. Libon

I.S. Baron

M.T. Schultheis

R.E. McCartney and A.Y. Stringer 


\section{Journal of the \\ International Neuropsychological Society}

\section{Volume 16}

Number 6

November 2010

\section{IN MEMORIAM}

951

Paul Satz, Ph.D. 1932-2010

\section{SHORT REVIEW}

953 Mild Traumatic Brain Injury and Postconcussive Symptoms in Children and Adolescents

\section{SYMPOSIA}

961 Introduction-Telling It Like It Isn't: The Cognitive Neuroscience of Confabulation

967 Confabulation in Alzheimer's Disease and Amnesia: A Qualitative Account and a New Taxonomy

975 Confabulations Are Emotionally Charged, but Not Always for the Best

984 Spontaneous Confabulation, Temporal Context Confusion and Reality Monitoring: A Study of Three Patients with Anterior Communicating Artery Aneurysms

995 Behaviorally Spontaneous Confabulation in Limbic Encephalitis: The Roles of Reality Filtering and Strategic Monitoring

1006 Memory Monitoring Failure in Confabulation: Evidence from the Semantic Illusion Paradigm

1018 Confabulation in Schizophrenia: A Neuropsychological Study

\section{RESEARCH ARTICLES}

1027 Emotions and Their Cognitive Control in Children with Cerebellar Tumors

1039 Positive Everyday Experiences Interact with Social Support to Predict Depression in Multiple Sclerosis

1047 Preliminary Evidence of Motor Impairment Among Polysubstance 3, 4-Methylenedioxymethamphetamine Users with Intact Neuropsychological Functioning

1056 Executive Dysfunction in Children with Neurofibromatosis Type 1: A Study of Action Planning

1064 Inhibitory Control and Psychopathology: A Meta-Analysis of Studies Using The Stop Signal Task

1077 Executive Function in Patients with Obstructive Sleep Apnea Treated with Continuous Positive Airway Pressure

1089 The Contribution of Injury Severity, Executive and Implicit Functions to Awareness of Deficits after Traumatic Brain Injury (TBI)
K.M. Heilman and J.M. Fletcher

K.O. Yeates

\section{A. Gilboa and M. Verfaellie}

V. La Corte, M. Serra, E. Attali, M-F. Boissé, and G. Dalla Barba

A. Bajo, S. Fleminger, and M. Kopelman

M.S. Turner, L. Cipolotti, and T. Shallice

L. Nahum, R. Ptak, B. Leemann, P. Lalive, and A. Schnider

I.P. Kan, K.F. Larocque, G. Lafleche, H.B. Coslett, and M. Verfaellie

E. Lorente-Rovira, J.L. Santos-Gómez, M. Moro, J.M. Villagrán, and P.J. McKenna

T. Hopyan, S. Laughlin, and M. Dennis

G.A. Vargas and P.A. Arnett

C.A. Bousman, M. Cherner, K.T. Emory, D. Barron, P. Grebenstein, J.H. Atkinson, R.K. Heaton, I. Grant, and The HRNC Group

A. Roy, J-L. Roulin, V. Charbonnier,

P. Allain, L. Fasotti, S. Barbarot, J-F. Stalder,

A. Terrien, and D. Le Gall

J. Lipszyc and R. Schachar

E.Y.Y. Lau, G.A. Eskes, D.L. Morrison, M. Rajda, and K.F. Spurr

N. Morton and L. Barker 